\title{
DESENHO CONTRATUAL EM PERSPECTIVA COMPARADA: REFLEXÕES SOBRE A RELAÇÃO ENTRE TIPIFICAÇÃO LEGAL E INOVAÇÃO CONTRATUAL
}

\section{CONTRACT DESIGN IN COMPARATIVE PERSPECTIVE: REFLEXIONS ON THE RELATIONSHIP BETWEEN LEGAL TYPIFICATION AND CONTRACTUAL INNOVATION}

\author{
Mariana Pargendler*
}

\begin{abstract}
RESUMO
As diferenças no estilo entre os modelos contratuais oriundos de sistemas romano-germânicos e de common law são bem conhecidas. Tradicionalmente, os instrumentos contratuais anglo-saxônicos são mais extensos, minuciosos e individualizados do que aqueles provenientes de países de tradição romanista. As razões para essas discrepâncias não são, porém, suficientemente compreendidas na literatura. O presente trabalho busca examinar como o papel proeminente dos tipos contratuais na tradição romanista e a sua menor relevância no common law repercute nos padrões de modelagem contratual observados na prática negocial. Do ponto de vista descritivo, a origem anglo-saxônica de expressiva parcela de contratos atípicos - como os contratos terminados em "-ing” (leasing, franchising, engineering, entre outros) - sugere a existência de fatores associados à tradição jurídica. Do ponto de vista normativo, verifica-se um tradeoff entre a redução dos custos de transação proporcionada pela padronização dos tipos contratuais, de um lado, e os desincentivos criados à inovação nas formas contratuais, de outro. Por fim, conclui-se por suscitar reflexão sobre o futuro das técnicas de redação contratual em tempos de globalização e sobre os possíveis papéis do Estado na indução da inovação contratual na tradição romano-germânica.
\end{abstract}

\section{PALAVRAS-CHAVE}

Desenho contratual. Tipos contratuais. Common law. Análise econômica.

\begin{abstract}
The differences in the style of contracts used in civil law and common law systems are well known. Traditionally, Anglo-Saxon agreements are longer, as well as more tailored and detailed, than those emerging from the civil-law tradition. However, the existing literature fails to provide a satisfactory explanation for this phenomenon. This article examines how the prominent role of contract types in the civil law tradition, and their lesser role in common law systems, affects the patterns of contract design observed in business practice. From a positive perspective, the Anglo-Saxon origin of a significant number of atypical contracts - such as the so-called “-ing” contracts (leasing, franchising, engineering, among others - suggests that the legal tradition may play an important role in shaping contract design. From a normative perspective, there is a tradeoff between a reduction in the transaction costs brought about by legislative contract types, on the one hand, and the

\footnotetext{
* Professora em tempo integral da Graduação em Direito, do Mestrado Acadêmico e do Mestrado Profissional em Direito da Escola de Direito de São Paulo da Fundação Getulio Vargas (FGV Direito SP. São Paulo, SP, Brasil), onde é diretora do Núcleo de Direito, Economia e Governança (NDEG). Global Associate Professor of Law na New York University (NYU) School of Law. Professora Visitante da Stanford Law School (2014-2015). Doutora (J.S.D.) e Mestre (LL.M.) em Direito pela Yale Law School. Doutora e Bacharel em Direito pela Universidade Federal do Rio Grande do Sul.E-mail: mariana.pargendler@fgv.br
} 
disincentives created to innovation in contractual forms, on the other. Finally, the article concludes by reflecting on the future of drafting techniques in an era of globalization and on the possible role of the state in inducing contract innovation in the civil law tradition.

\section{KEYWORDS}

Contract design. Contract types. Common law. Economic analysis. 


\section{INTRODUÇÃO}

As diferenças e as semelhanças entre os sistemas jurídicos de tradição romano-germânica, de um lado, e de common law, de outro, cativam os juristas de todo o mundo. Há muito se observa que os diferentes sistemas jurídicos divergem não somente no que diz respeito ao direito positivo dos contratos, mas igualmente no que toca às práticas e cláusulas contratuais habitualmente utilizadas no ambiente de negócios. Em que pese a forte tendência de convergência em tempos de globalização, os contratos oriundos do mundo anglo-saxônico são tradicionalmente mais longos e minuciosos do que aqueles redigidos em países de origem romano-germânica ${ }^{1}$.

Há diferentes teorias que buscam explicar a maior prolixidade dos instrumentos contratuais em países de common law - e especialmente nos Estados Unidos ${ }^{2}$ - relativamente àqueles oriundos do direito continental ${ }^{3}$. O comparatista e historiador do direito John Langbein (1987, p. 387) atribui a diferença na extensão dos contratos na Alemanha e nos Estados Unidos ao que ele denomina de “vantagem comparativa alemã” no campo do processo civil. Diferentemente dos Estados Unidos, a Alemanha conta com um judiciário profissional imune às distorções típicas do sistema processual norte-americano, como júris populares, excessos procedimentais na fase de discovery e incentivos à propositura de lides temerárias pela ausência de honorários de sucumbência. Diante da eficiência do sistema processual, as partes de um contrato na Alemanha teriam menos resistência à utilização da via judicial em caso de desentendimento relativo ao negócio e, por conseguinte, redigiriam contratos mais enxutos e potencialmente mais suscetíveis a interpretações divergentes (LANGBEIN, 1987, p. 390)4. Já nos Estados Unidos, os contratantes, temerosos quanto ao “catálogo de horrores procedimentais” que aflige o direito processual do país, tentariam disciplinar suas obrigações da forma mais detalhada possível, de modo a prevenir potenciais litígios (LANGBEIN, 1987). As cláusulas-padrão nos contratos (boilerplate) seriam o verdadeiro “mos Americanus” (LANGBEIN, 1987, p. 391).

\footnotetext{
1 Cf., p. ex., CALKOEN, 2001; HENROT, 1990; HILL; KING, 2004, p. 889; LANGBEIN, 1987, p. 381; LUNDMARK, 2001, p. 121; VAN HECKE, 1962, p. 5-10.

${ }^{2}$ Em verdade, a redação de contratos longos e repletos de jargões padronizados (boilerplate) apresenta-se como marca registrada do estilo de advocacia consultiva nos Estados Unidos. Como observa John Langbein, os contratos ingleses tendem a ser mais longos do que aqueles produzidos no continente, mas mais curtos do que os norte-americanos (LANGBEIN, 1987).

${ }^{3}$ Conquanto a literatura existente sobre este tema concentre-se quase exclusivamente nos Estados Unidos e Alemanha, é possível tecer generalizações para outros sistemas de tradição anglo-saxônica e romanista.

${ }^{4}$ Na terminologia de Scott e Triantis, os advogados romanistas, por confiarem na eficiência do sistema judicial, preferem economizar custos no momento inicial (redigindo contratos mais curtos) e alocá-los no momento final (resolvendo judicialmente as circunstâncias que o contrato não prevê), enquanto os advogados anglo-saxões preferem a alocação inversa (SCOTT; TRIANTIS, 2006, p. 796).
} 
Outros autores elencam fatores adicionais para a menor extensão dos instrumentos contratuais na Alemanha. Para Claire Hill (2004, p. 899-915), a diferença também se deve ao papel mais amplo do dever de boa-fé no direito alemão, o qual tem por função suprir lacunas contratuais e prevenir, com menos palavras, comportamentos oportunistas. Thomas Lundmark (2001, p. 131), por sua vez, considera que o papel proeminente da boa-fé e o menor campo de atuação concedido à autonomia privada na Alemanha tornariam fúteis as tentativas de influenciar o desfecho de uma eventual lide por meio de cláusulas detalhadas. Consequentemente, as partes poupariam tempo e recursos e redigiriam contratos mais curtos.

Todavia, é fácil exagerar a relevância dos fatores acima expostos. Conquanto se reconheça a influência de aspectos procedimentais e o papel proeminente da boa-fé como cânone interpretativo e integrativo nos países de civil law, esses elementos são insuficientes para explicar as diferenças observadas nas práticas contratuais. Aliás, o debate existente tem sido moldado por um prisma excessivamente restrito, que se concentra exclusivamente na extensão dos instrumentos contratuais, em detrimento de outras diferenças igualmente importantes, como o grau de inovação nos arranjos contratuais. Este trabalho busca contribuir para o debate sobre a comparação entre práticas contratuais por meio da análise de um outro fator que vem sendo negligenciado pelos estudiosos do tema: a maior relevância da técnica de tipificação de contratos no direito continental.

Tem-se como hipótese principal que a tipificação pode ser um fator explicativo para as diferenças nos modelos contratuais habitualmente empregados nas duas grandes tradições jurídicas ${ }^{5}$. Defende-se, de um lado, que a existência de contratos típicos frequentemente torna desnecessário - e, em alguns casos, contraproducente - o regramento pormenorizado das condições do negócio. De outro, sugere-se que, conquanto poupe custos de transação, especialmente os custos de redação contratual, a ênfase, nos países de direito continental, em contratos típicos e em normas específicas previstas em lei tende a reduzir o incentivo para a redação e a inovação contratual nesses sistemas, relativamente aos de common law. Diante da existência de contratos típicos - e da importância conferida à disciplina constante do diploma legal -, os operadores do direito no civil law costumam conceber o fenômeno contratual por meio de suas diversas categorias, ao passo que os operadores do direito com formação em common law tendem a vislumbrar no contrato um fenômeno unitário. Essas diferentes formas de pensar geram, por conseguinte, diferentes estilos de redação contratual.

\footnotetext{
${ }^{5}$ Cumpre, porém, reconhecer que as ditas “tradições jurídicas” são, em um sentido importante, inventadas. Para uma análise da evolução histórica das classificações de famílias jurídicas cf. PARGENDLER, 2012.
} 
A parca atenção conferida pela literatura aos tipos contratuais deve-se, ao menos em parte, à percepção de que a diferença quanto à tipificação ou não dos contratos seria sutil e quiçá pouco relevante. Isso porque parcela significativa das regras sobre contratos típicos constantes do Código Civil não seriam, em princípio, cogentes, e sim dispositivas, tendo sua incidência afastada em face de disposição contratual em contrário. Ademais, cumpre também ressaltar que a diferença observada é somente de grau. Nos Estados Unidos, por exemplo, o título segundo do Uniform Commercial Code traz disciplina específica aos contratos de compra e venda de mercadorias aplicável em todo o território norte-americano. Os contratos de sociedade igualmente se sujeitam a regras legais próprias promulgadas por diferentes estados da federação. A common law, por sua vez, deduz termos contratuais (implied terms) aplicáveis somente a algumas espécies de contratos, como a garantia implícita de habitabilidade (implied warranty of habitability) inerente a contratos de locação residencial. Porém, o fato de as diferenças observadas serem apenas relativas não afasta, de modo algum, a sua relevância. Afinal, o direito comparado é justamente o estudo de diferenças relativas ${ }^{6}$.

O tema será analisado da seguinte forma. A segunda parte oferece um breve panorama sobre a centralidade dos contratos típicos em países de tradição romanista. A terceira parte apresenta uma sucinta digressão histórica para demonstrar como a visão unitária do fenômeno contratual no common law e a concepção fragmentária do civil law foram desenvolvidas ao longo do tempo e sobreviveram até o presente. Na quarta parte, examinam-se o valor segurança jurídica e o papel central da doutrina na tradição romano-germânica como fatores que intensificam a importância dos tipos contratuais neste sistema. A quinta parte emprega alguns dos postulados teóricos da literatura de direito e economia (cf. SALAMA, 2008) para examinar o porquê da importância dos tipos contratuais para operações econômicas, bem como para avaliar as vantagens comparativas de ambos os sistemas. Por fim, a sexta e última parte conclui com algumas previsões sobre o impacto do fenômeno conhecido como a "americanização do direito" sobre os tipos contratuais e as estratégias de redação contratual.

\footnotetext{
${ }^{6}$ No dizer de James Whitman, "the issue is not whether there is an absolute difference. Comparative law is the study of relative differences. Indeed, it is the great methodological advantage of comparative law that it can explore relative differences. No absolute generalization about any legal system is ever true” (WHITMAN, 2004, p. 1.151-1.163).
} 


\section{CONTRATOS TÍPICOS E ATÍPICOS: A IMPORTÂNCIA DA DISTINÇÃO NA TRADIÇÃO ROMANO-GERMÂNICA}

A existência de um código civil é o marco paradigmático de um sistema jurídico afiliado à tradição romano-germânica em tempos atuais. Por sua vez, é um traço característico da codificação civil conter tanto os aspectos relacionados ao regime jurídico geral aplicável a negócios jurídicos e contratos (como os requisitos de validade do negócio jurídico, a formação do vínculo contratual, as consequências do inadimplemento, entre outros) como normas específicas aplicáveis aos diferentes tipos de contrato (compra e venda, fiança, comodato, entre tantos outros). Cada tipo contratual disciplinado reflete, em princípio, uma categoria diferente de operação econômica (ROPPO, 1988, p. 133). Por exemplo, o Código Civil brasileiro de 2002 consagra e regula nada menos do que 23 tipos de contratos.

Nos sistemas jurídicos de tradição continental, a clássica summa divisio em matéria de contratos é aquela entre contratos típicos e contratos atípicos ou, para os países que continuam a utilizar a nomenclatura romana, entre contratos nominados e inominados. Embora os diferentes países de tradição romano-germânica divirjam quanto ao rol de contratos típicos contemplados por lei e quanto à importância da classificação entre contratos típicos e atípicos, há, sem dúvida, elementos comuns. Se um contrato é típico, ele será regido pelas normas legais se as partes não fizerem estipulação em contrário - e, em alguns casos, ainda que o façam. Já os contratos atípicos são, via de regra, sujeitos a suas próprias cláusulas e aos princípios gerais dos contratos, aplicandose analogicamente, em alguns países, as regras dos contratos típicos com os quais guardam maior semelhança. No Brasil, determina o art. 422 do Diploma Civil que “é lícito às partes estipular contratos atípicos, observadas as normas gerais fixadas neste Código”. Diante da distinção entre contratos típicos e atípicos, os operadores do direito têm de confrontar, de pronto, duas questões fundamentais: (i) a qualificação do contrato como atípico ou típico e, no último caso, a identificação do contrato típico em questão e (ii) a identificação do caráter dispositivo ou cogente das regras sobre contratos típicos constantes do Código Civil e da legislação esparsa.

Quanto à qualificação jurídica do contrato, são vários os elementos que tornam a tarefa mais complexa do que um exame apressado faria supor. Em primeiro lugar, a denominação conferida pelas partes aos contratos é irrelevante para a sua classificação. Ainda que as partes chamem um contrato $x$, pode o julgador considerar que, em essência, se está diante de um contrato 
$y$, suscitando a aplicação do regime jurídico pertinente a esse último ${ }^{7}$. Além disso, um contrato atípico pode ser qualificado como misto, sempre que combinar elementos essenciais de dois ou mais contratos típicos - situação na qual se aplicam as regras dos respectivos contratos típicos a seus diferentes elementos. Somente o contrato atípico verdadeiramente sui generis se rege apenas pelas suas cláusulas e pelos princípios gerais de direito contratual ${ }^{8}$. Ainda assim, como será visto adiante, até mesmo os contratos sui generis podem vir a ser objeto de estudos acadêmicos sobre sua normatização, o que pode levar ao surgimento de novas normas, dispositivas ou cogentes, a eles aplicáveis ${ }^{9}$.

A caracterização das normas legais referentes a contratos típicos como dispositivas ou cogentes é igualmente intrincada. De acordo com a visão clássica predominante durante o liberalismo oitocentista, que erigia a liberdade de contratar como valor supremo, as regras contidas nos códigos teriam, no mais das vezes, natureza dispositiva, isto é, suscetível de derrogação pela vontade das partes. Com o declínio do dogma da autonomia da vontade e o crescente prestígio do dirigismo contratual, a lógica por vezes se inverte, sobretudo no que diz respeito a diplomas legais que visam à proteção da parte mais vulnerável da relação contratual, como, no Brasil, a Consolidação das Leis do Trabalho de 1943, a Lei do Inquilinato e o Código de Defesa do Consumidor, ambos de 1990, entre tantos outros. Logo, nem sempre é fácil discernir o caráter cogente ou dispositivo de uma dada norma, mormente porque, diferentemente da técnica legislativa empregada alhures, os diplomas legais brasileiros em muitos casos deixam de elucidar a questão. Como resultado, compete ao intérprete verificar, em cada caso, a existência ou não de questão de ordem pública a justificar ingerência estatal no âmbito da autonomia privada.

Ademais, a doutrina enfatiza que o caráter supletivo das normas legais relativas aos contratos típicos não reduz a sua importância prática. Sustenta-se, nesse sentido, que são poucos os contratos que contêm disposição expressa sobre todos os pontos regulados por lei. Embora não haja óbices jurídicos para que as partes estipulem as cláusulas que preferirem, defendem os autores que, tratando-se de contrato típico, seria supérfluo fazê-lo (VASCONCELLOS, 1995, p. 365).

Embora a existência de tipos contratuais seja generalizada entre países de tradição continental, há variação na importância da distinção entre contratos típicos e atípicos em diferentes países. O Código Civil italiano de 1942 sublinha a distinção de forma mais drástica. Promulgado no

\footnotetext{
${ }^{7}$ Henrot (1990, p. 56-57) cita que o Tribunal de Apelação de Paris decidiu que um contrato chamado pelas partes de acordo de parceria era, na verdade, uma venda de ações na qual o vendedor conservava alguns dos direitos habituais dos acionistas, ainda que as partes nunca tivessem pensado numa tal classificação.

${ }^{8}$ Cf., p. ex., AYNES; MALAURIE, 1989.

${ }^{9}$ Ver Parte IV, infra.
} 
ápice da era fascista, o art. 1.322 do diploma italiano determina que as partes somente podem celebrar contratos atípicos que concretizem interesses merecedores de tutela segundo o ordenamento jurídico ${ }^{10}$.

Para Emilio Betti, eminente civilista contemporâneo ao Codice Civile, tal regra exige que as partes provem objetivamente a existência de um interesse geral de ordem econômica e social, acompanhado de uma prática generalizada. Defende o autor que a liberdade para escolher os tipos contratuais nem de longe implica uma liberdade absoluta para prever todo e qualquer conteúdo. Ao contrário, significa apenas que as partes podem escolher entre os tipos legais e entre práticas sociais estabelecidas. Betti (1991, p. 325) ${ }^{11}$ defende expressamente que, tal como no direito romano, negócios atípicos que se resumam a “impulsos esporádicos”, sem a corroboração de uma prática social consolidada, não seriam tutelados pelo sistema jurídico.

Embora a Itália represente, em muitos aspectos, o arquétipo de um país de tradição romanista (MERRYMAN, 1985, p. 57), tal tratamento radical jamais foi predominante em outros sistemas de civil law. Os códigos civis oitocentistas introduziram tipos contratuais como uma herança do direito romano, não como um instrumento para a imposição de uma ideologia coletivista. Outros países de direito romano-germânico reconhecem que as partes têm direito a celebrar contratos atípicos quando lhes parecer conveniente, desde que estes não violem os princípios gerais de direito contratual. O Código Civil brasileiro de 2002 prevê expressamente esse regime no seu art. 425. É certo que a pactuação de contratos atípicos já era amplamente admitida no diploma anterior, de 1916, mas o próprio fato de o legislador julgar relevante tecer semelhante consideração apenas corrobora a importância da distinção entre contratos típicos e atípicos em países de tradição romano-germânica.

\section{TIPICIDADE CONTRATUAL EM PERSPECTIVA HISTÓRICA NAS DIFERENTES TRADIÇÕES JURÍDICAS}

A distinção entre contratos típicos e atípicos remonta ao direito romano. Inicialmente, no período pré-clássico do direito romano, do simples acordo de vontades não nascia, na ausência de certas formalidades, o direito de ação - ex nudo pacto actio non nascitur. Por força da natureza

\footnotetext{
${ }^{10}$ C. C., art. 1.322: “Autonomia contrattuale - Le parti possono liberamente determinare il contenuto del contratto nei limiti imposti dalla legge (e dalle norme corporative). Le parti possono anche concludere contratti che non appartengano ai tipi aventi una disciplina particolare, purché siano diretti a realizzare interessi meritevoli di tutela secondo l’ordinamento giuridico".

${ }^{11}$ Publicado originalmente em 1944 em alemão com o título "Der Typenzwang bei den römischen Rechtsgeschäften und die sogennante Typenfreiheit des heutigen Rechts”.
} 
procedimental do direito romano, o sistema jurídico tutelava o cumprimento apenas de contratos nominados (compra e venda, comodato, depósito, etc.). Foi somente com o surgimento da república que o direito romano passou a reconhecer ações de natureza restituitória relativamente a contratos inominados (MERRYMAN, 1985, p. 15-16).

Longe de conceber o fenômeno contratual de forma unitária e abstrata, o jurista romano vislumbrava tão somente espécies concretas de contratos sujeitas a regimes jurídicos autônomos. A obrigação, no direito romano, não decorria da manifestação subjetiva da vontade das partes, mas, ao contrário, derivava de um elemento objetivo: a observância das formalidades prescritas em cada caso ou a entrega da coisa. O termo "contractus” referia-se à relação jurídica entre as partes; o simples acordo de vontades não era tutelado por uma ação afirmativa (actio), mas apenas como uma defesa (COSTA, 1998, p. 185).

Posteriormente, durante a república, os contratos inominados passaram a ser exigíveis com base na ideia de que, tendo uma das partes cumprido com a sua parte do acordo, há causa, o que obriga a outra a cumprir o acordado (MALAURIE et al., 1989, p. 12; MICHELON JR., 2007, p. 19). Contudo, a exigibilidade de contratos atípicos era ainda assim limitada. Ao longo de sua evolução, o direito romano manteve o princípio da tipicidade dos contratos, que eram, em princípio, numerus clausus.

Nos séculos XVII e XVIII, os tribunais franceses e alemães, apesar das regras de direito romano, já conferiam exigibilidade aos contratos inominados (GORDLEY, 1998, p. 68). Contudo, foi somente ao final desse período que se deu uma maior ruptura com os precedentes formalistas, com o surgimento de uma teoria voluntarista do contrato, sob os auspícios de Domat e Pothier, os autores franceses responsáveis pela abstração dos particularismos e pela criação de uma categoria geral de contrato (COSTA, 1998, p. 187). Tal transformação, no entanto, não afastou a marcante influência do direito romano quanto à terminologia, aos fundamentos teórico-normativos e às regras específicas aplicáveis a determinados tipos de contratos (LANGUI, 1987).

A evolução do contrato no common law seguiu trajetória bastante distinta. Compare-se, por exemplo, a variedade de formalidades que eram exigidas no antigo direito romano ao equivalente mais próximo do significado moderno de contrato entre os velhos writs de common law: o writ of Covenant. O writ of Covenant era dirigido à Court of Common Pleas e significava simplesmente um acordo. Era uma ação por inadimplemento de uma promessa de fazer algo no futuro. O remédio inicialmente disponível era o cumprimento específico, o qual foi posteriormente substituído por perdas e danos (TEEVEN, 1990, p. 5-6). 
Outro conjunto das antigas ações pessoais foi agrupado na ação por dívida (Debt), que a praxe tornou disponível antes mesmo do Covenant. Na ação por dívida, o autor exigia não apenas o cumprimento de uma promessa, mas a restituição de coisa a ele pertencente e que o réu detinha ilegalmente (TEEVEN, 1990, p. 7). Outro writ, o Detinue, que visava a um bem supostamente pertencente ao autor mas que estava em posse do réu, também tinha um caráter muito geral. A última ação pessoal dessa época é a Account, um praecipe writ que ordenava ao xerife que mandasse os réus, agindo na qualidade de mandatários e trustees, prestar contas de dinheiro do autor que detivessem em suas mãos (TEEVEN, 1990, p. 11).

O divisor de águas que marcou a substituição dos velhos writs contratuais pelo Assumpsit como ação contratual geral para o cumprimento de promessas informais foi o caso Slade (TEEVEN, 1990, p. 50 $)^{12}$. Na década de 1580 , a consideration já se tornara a doutrina consagrada para determinar quando o cumprimento de uma promessa podia ser exigido por meio de Assumpsit (TEEVEN, 1990, p. 53). Essa breve digressão histórica mostra que os antecedentes dos contratos no common law nunca tiveram a conformidade com tipos contratuais preestabelecidos como condição para a sua exigibilidade; esta última dependia apenas de requisitos gerais aplicáveis a diferentes modalidades de contrato.

No século XIX, o direito contratual nos Estados Unidos era essencialmente negativo: o que as partes haviam acordado livremente seria aplicado pelos tribunais. Além desse princípio elementar, havia certas regras concretas sobre a formação e a interpretação dos contratos, mas as velhas formalidades haviam sido descartadas muito antes de 1850 (FRIEDMAN, 2005, p. 404). À época havia prevalecido, tanto nos Estados Unidos quanto na Europa continental, a “teoria voluntarista”, que concebia o contrato como, fundamentalmente, um produto da vontade das partes (GORDLEY, 1998).

A tradição de common law sempre conferiu mais ênfase às normas gerais aplicáveis a todos os contratos (ou pelo menos à maioria deles), ao passo que o civil law sempre manteve suas regras especiais para diferentes tipos de contratos. Consequentemente, a formação dos juristas anglo-saxões volta-se para os princípios gerais dos contratos. Por outro lado, a educação jurídica num país de direito romano-germânico usualmente contempla, além de uma parte geral acerca das regras comuns a todas as espécies de contratos, uma parte especial sobre os diferentes tipos contratuais (“contratos em espécie”).

\footnotetext{
${ }^{12}$ Slade v. Morley, 4 Co. Rep. 91a, 76 Eng. Rep. 1072 (1602).
} 
Na mesma linha, os tratados anglo-saxões sobre contratos cuidam unicamente das regras gerais $^{13}$, enquanto os estudos continentais costumam dedicar uma parcela significativa de atenção ao regime aplicável aos contratos típicos (e, por vezes, também aos atípicos). Além disso, os manuais de redação contratual e os modelos de petições oriundos de países de common law concentram-se com mais frequência no contrato como fenômeno unitário ${ }^{14}$. Suas orientações habitualmente contemplam questões recorrentes em qualquer modalidade contratual. A ênfase recai sobre as cláusulas e disposições gerais, aplicáveis à maioria dos contratos, incluindo-se as cláusulas recorrentes, verdadeiro jargão contratual (boilerplate). No direito romano-germânico, inversamente, os modelos de petições ensinam a formalizar tipos específicos de contratos. A tendência, mais uma vez, é no sentido de tratar os contratos como uma realidade fragmentada: os manuais de redação jurídica na tradição continental quase sempre privilegiam tipos jurídicos e sociais em vez de questões gerais ${ }^{15}$.

A preferência relativa do sistema romano-germânico pelo uso de tipos formais de contrato, contrastada com a tendência do direito norte-americano de lidar com os contratos por meio de regras gerais, também é visível com relação ao controle social de cláusulas contratuais abusivas. A maioria dos países de civil law estipulou que certos tipos de cláusulas (como cláusulas arbitrais e de exclusão de responsabilidade, entre outras) são abusivas e, por conseguinte, nulas de pleno direito quando inseridas em relações de consumo ${ }^{16}$.

Nos Estados Unidos ${ }^{17}$, todavia, questões de proteção do consumidor ou de abusividade são normalmente tratadas por meio de doutrinas fluidas, tais como a da unconscionability ${ }^{18}$, que exige,

\footnotetext{
${ }^{13}$ Cf., p. ex., FARNSWORTH, 2004, que divide o tema em partes gerais, como a exigibilidade de promessas, o alcance e o efeito de promessas, os direitos de terceiros e o cumprimento de promessas. FARNSWORTH, 1979, também lida com regras gerais aplicáveis à maior parte ou a todos os tipos de contratos.

${ }^{14}$ Para manuais norte-americanos de redação contratual que tratam os contratos como fenômeno unitário e enfocam questões comuns aos diferentes tipos de contratos, cf., p. ex., STARK, 2003; BURNHAM, 1992. Para um exemplo de manual de redação jurídica romanista que trata de espécies de contratos, ver DINIZ, 2003.

${ }^{15}$ Para uma definição de tipos jurídicos e sociais, cf. Parte IV, infra.

16 A Diretiva da União Europeia sobre cláusulas abusivas em contratos celebrados com consumidores (Diretiva do Conselho 93/13/EEC, de 5 de abril de 1993) adota uma postura intermediária. Seu artigo 3 estipula os critérios gerais para determinar se uma cláusula é abusiva (e, portanto, nula) e o anexo fornece uma lista não exaustiva de cláusulas específicas que podem ser consideradas abusivas.

17 A Inglaterra, por outro lado, apresenta um panorama diferente. Diplomas como a Lei de Cláusulas Contratuais Abusivas (Unfair Contract Terms Act) de 1977 especificam diversas cláusulas que são nulas nos contratos empresariais. Mais uma vez, a Inglaterra possui características intermediárias entre os EUA e os países continentais.

${ }^{18}$ De fato, a versão de unconscionability inspirada pelo realismo jurídico e adotada pelo Uniform Commercial Code (Código Comercial Uniforme) nem mesmo tenta definir seu significado ("§ 2-302. Contrato ou cláusula desproporcional. (1) Se o tribunal concluir, em matéria de direito, que o contrato ou qualquer cláusula do contrato era desproporcional à época em que foi feito, o tribunal poderá se recusar a aplicar o contrato, ou poderá aplicar o restante do contrato sem a cláusula desproporcional, ou poderá limitar a aplicação de qualquer cláusula desproporcional de modo a evitar qualquer resultado desproporcional. (2) Quando for alegado ou parecer ao tribunal que o contrato ou
} 
além da “abusividade” da cláusula (desproporcionalidade material), um exame casuístico da disparidade do poder de barganha e da natureza do processo de negociação ${ }^{19}$. Em Carnival Cruise Lines v. Shute (499 U.S. 585 [1991]), por exemplo, a Suprema Corte norte-americana reconheceu a validade de uma cláusula de eleição de foro em um contrato de consumo. Os autores da ação haviam comprado passagens para um cruzeiro e elas foram entregues pelo correio, que continha uma cláusula de eleição de foro. A corte sustentou que não era fundamentalmente abusivo exigir que os autores movessem a ação na Flórida, pois eles haviam tido a oportunidade razoável de ler o contrato num período em que podiam devolver as passagens e obter o reembolso integral. O estilo do sistema norte-americano pende novamente em favor da individualização do regime aplicável no caso concreto, enquanto os sistemas romanistas preferem ater-se a regras jurídicas de natureza geral, formuladas em categoria abstrata.

\section{O PAPEL DA DOUTRINA E DO IDEAL DE SEGURANÇA JURÍDICA}

Por si só, a tipificação legal de diferentes contratos não explica inteiramente a importância da distinção entre contratos típicos e atípicos. Uma parte significativa da rigidez imposta à modelagem contratual deve-se, ainda que não intencionalmente, ao papel dos estudos jurídicos nessa área. De fato, embora se possa supor que o protagonismo na tradição romano-germânica recai sobre o legislador, os comparatistas advertem que essa pressuposição é enganadora. Com efeito, “o professor-doutrinador é o verdadeiro protagonista da tradição romanista. O civil law é um direito dos professores” (MERRYMAN, 1985, p. 56).

Referida a importância da doutrina para a rigidez dos tipos contratuais, cumpre indagar por que isso acontece. De uma perspectiva histórica, os doutrinadores do início do século XX criticaram fortemente a classificação de um contrato como atípico quando ele inicialmente não parecia se enquadrar nos tipos do código (DE NOVA, 1974, p. 15-16). O tratamento metodológico correto, afirmavam, seria tentar reiteradamente encaixar os novos esquemas contratuais nos tipos do código. Ainda que essa tendência fosse mais visível na Itália, os comentadores brasileiros exibiam atitude semelhante (PINTO, 1943, p. 14-15) ${ }^{20}$. As declarações do célebre jurista francês Planiol fornecem

qualquer uma de suas cláusulas pode ser desproporcional, será outorgada às partes uma oportunidade razoável de produzir provas de seu contexto comercial, finalidade e efeito para auxiliar o tribunal a fazer a determinação”).

${ }^{19}$ Cf., p. ex., Gillman v. Chase Manhattan Bank, 73 NY2d, 1, 10, e Matter of State of New York v. Avco Fin. Servs., 50 NY2d 383, 389.

${ }^{20}$ Afirma o autor que “[n]ada [é] mais louvável do que o constante esforço dos verdadeiros juristas que, a todo custo, procuram manter inalterada a sólida construção que herdamos da intuição jurídica dos romanos e dos longos séculos de 
um exemplo eloquente do forte apego dos doutrinadores romanistas aos tipos contratuais do código. Em 1904, Planiol afirmou a impossibilidade de criar novos contratos verdadeiramente atípicos; todas as formas contratuais, em verdade, poderiam ser relacionadas a um tipo ou a uma combinação de tipos conhecidos (PLANIOL, 1904, p. 487-88) ${ }^{21}$.

Hoje, essa prática extrema caiu em desuso. Ainda assim, a doutrina continua a desempenhar um papel fundamental para incrementar a importância dos tipos contratuais de duas maneiras diferentes. Em primeiro lugar, a profusão de livros e artigos sobre contratos típicos e atípicos expande o conteúdo das leis e confere autoridade considerável a certas modalidades de contratos atípicos. Em segundo lugar, a classificação doutrinária de determinados contratos - como, por exemplo, leasing e built-to-suit -, como juridicamente atípicos, mas socialmente típicos, aproxima tais formas da maior rigidez associada aos tipos contratuais.

Os doutrinadores romanistas, com seu pendor para a certeza e as categorizações dogmáticas, dedicam uma parcela considerável de seu tempo a classificar, definir e distinguir os diferentes contratos. Além disso, os autores escrevem uma enorme quantidade de livros e artigos também sobre contratos atípicos ${ }^{22}$. A estrutura desses trabalhos é curiosa: descreve-se amiúde as cláusulas distintivas, os objetivos do contrato e a distribuição dos riscos, muito embora, estritamente falando, não haja qualquer disciplina legal sobre tais questões ${ }^{23}$.

O fato de a doutrina dedicar muito esforço a comentários sobre o código e outros diplomas legislativos que regulam os contratos típicos é natural, dado o caráter precipuamente dogmático da literatura jurídica no civil law ${ }^{24}$. No entanto, a ênfase nos contratos atípicos é mais surpreendente, já que a ausência de disciplina jurídica específica sugeriria que o contrato seria regido unicamente pelas suas cláusulas e pelas disposições gerais do direito contratual. Mas é o contrário que ocorre: os doutrinadores dedicam uma quantidade extraordinária de atenção aos contratos atípicos, talvez

experiência e de elaboração científica que nos precederam. Contrasta agradavelmente esse esforço com a preguiça ou indiferença daqueles que comodamente procuram lançar, logo à primeira dificuldade, qualquer tipo de contrato menos conhecido ou ainda não perfeitamente caracterizado, na já imensa classe dos contratos chamados inominados, como se fosse esse um meio de tornar desnecessária a construção teórica em torno da nova espécie de convenção” (PINTO, 1943, p. 14-15).

${ }^{21}$ No original, “c'est à tort qu'on a soutenu que l’on pouvait encore créer des contrats innommés et nouveaux”.

${ }^{22}$ No Brasil, cf., p. ex., MARTINS, 2000 (sobre leasing, seguro, franchising, know-how, cartões de crédito, etc.) e BITTAR, 2003 (com mais de 30 contratos).

${ }^{23}$ Para uma amostra muito breve dessas obras infinitas, cf., na Espanha, GARCÍA, 1990, p. 137; ORTIZ, 1971 , p. 73. No Brasil, FREIRE; MEZZOMO, 2001, p. 125; THEODORO JÚNIOR, 2004, p. 121; AZEVEDO, 2005, p. 239. Na Itália, LAPERTOSA, 1993; CAGNASSO, 1993; IRRERA, 1993. E, na França, NICOLAS; TROGAN, 1966.

${ }^{24}$ A doutrina romanista nunca sofreu os ataques severos do realismo jurídico, que acabou revolucionando o caráter dos estudos jurídicos nos EUA. Embora a crença de que a doutrina pode alcançar uma decisão correta e neutra tenha sido muito mais desmoralizada nos Estados Unidos, ela continua a ter um prestígio significativo nos países de civil law. Portanto, o viés românico da ciência jurídica é eminentemente doutrinário, embora isso venha mudando significativamente em tempos recentes. Sobre essas mudanças, cf. PARGENDLER; SALAMA, 2013. 
numa tentativa desesperada de fazer com que o "law in the books" se aproxime da realidade. O alvo favorito da atenção acadêmica são os chamados contratos terminados em “-ing” (leasing, franchising, engineering, factoring, shopping center e assim por diante), cuja denominação em inglês revela sua origem anglo-saxônica (AUDIT, 2001, p. 7-9) ${ }^{25}$.

O segundo modo como a doutrina reforça a importância dos contratos típicos é por meio do conceito de contratos socialmente típicos. Sustenta-se que, além daqueles juridicamente típicos, existem certos contratos que, embora juridicamente atípicos, são tão comuns e uniformes na prática negocial que se tornam socialmente típicos. Esse tipo de observação parece, à primeira vista, inofensivo: embora não contemplados pela legislação, certos contratos são, na prática, muito comuns e homogêneos. Mesmo sem essa classificação, práticas disseminadas ainda seriam relevantes à luz dos usos comerciais, que servem de critério de interpretação e integração contratual tanto nos países de civil law como nos de common law. Contudo, ao classificar esses contratos como "socialmente típicos", a doutrina confere a essas formas recorrentes um impulso adicional, que deriva da importância dos contratos típicos e da ambiguidade na classificação dessas regras como cogentes ou dispositivas.

Por fim, também é sugestiva a recorrência com que os trabalhos acadêmicos instam o legislador a fornecer uma consolidação legal da prática dos contratos atípicos. Muitas vezes, alegase “[...] a necessidade de se consubstanciar na lei uma orientação segura para os institutos jurídicos” (AZEVEDO, 1975, p. 173). Exemplos dessa tendência incluem a insistência na regulação legal de contratos de engineering, de shopping center e assim por diante ${ }^{26}$.

A preferência pela regulação legal está estreitamente ligada à preocupação dos doutrinadores com os riscos da liberdade excessiva. Álvaro Villaça Azevedo chegou a afirmar que “[...] se o problema dos romanos foi o de forçar o aparecimento das formas de contratos atípicos, o nosso é de não deixá-los ao livre arbítrio das partes, ante o perigo de uma liberdade não condicionada” (AZEVEDO, 1975, p. 121-122) e que “[a] liberdade há que condicionar-se, emoldurando-se na lei, para ser liberdade condicionada, não ser liberdade escravidão [...]” (AZEVEDO, 1975, p. 178). Schapp, um doutrinador alemão, declarou que um contrato em que as

\footnotetext{
${ }^{25}$ Bernard Audit (2001, p. 7-9), mencionando “les contrats en 'ing'”.

${ }^{26}$ Por exemplo, o célebre jurista gaúcho Clóvis do Couto e Silva instou o legislador a regular os contratos de engineering a fim de lhes conferir maior transparência, o que exigiria a criação de um tipo, como aconteceu com o contrato de viagem alemão (Reisevertrag) (BGB, 651) (“[...] é imperiosa a edição de uma lei especial, que consolide as disposições, usualmente trazidas nestes contratos, não deixando de inserir cláusulas gerais que adaptem a sua aplicação às hipóteses sempre imprevisíveis, mas que vêm necessariamente a ocorrer”). Cf. SILVA, 1997, p. 135.
} 
partes ab-rogassem todas as regras dispositivas por meio da negociação individual seria um monstro (apud VASCONCELLOS, 1995).

Na prática, muitas das principais inovações contratuais contemporâneas surgiram nos países de common law, especialmente nos Estados Unidos, e posteriormente foram de lá exportadas para o universo romano-germânico. Como elas já constituíam prática consolidada, foram tidas como contratos atípicos, mas socialmente típicos, suscitando poucas dúvidas sobre a sua legitimidade. Como a certeza favorece a aplicação do que se tornou comum, as inovações que são prática comum nos Estados Unidos enfrentam barreiras consideravelmente menores. É o que o renomado comercialista italiano Francesco Galgano denominou de "validade dos contratos atípicos com circulação internacional”27.

Em decorrência disso, a postura conservadora dos juristas e as exigências objetivas de certeza $^{28}$ levam a um fenômeno de inércia das formas contratuais: a tentativa de ater-se a terrenos consolidados e de enfrentar novos problemas usando esquemas já conhecidos (DE NOVA, 1974, p. 3). O clima é de reverência aos tipos legislativos, considerados uma espécie de forma ideal à qual os contratos inominados devam se adaptar (DE NOVA, 1974, p. 4). A tendência de reconciliar cada contrato, por meio do processo de tipificação, com os esquemas familiares dos contratos típicos (DE NOVA, 1974, p. 3), conduz fortemente a uma menor originalidade na redação contratual. Por conseguinte, os tipos contratuais, combinados com uma mentalidade “tipificadora” (mentalità tipizzante) (DE NOVA, 1974, p. 5), tornam os países de direito romano-germânico menos propícios a inovações contratuais.

\section{CONTRATOS TÍPICOS E MODELAGEM CONTRATUAL COMPARADA}

Da descrição feita até aqui, tem-se que não se pode menosprezar a existência dos tipos contratuais para entender o processo de modelagem contratual nos países de direito romanogermânico. Os tipos contratuais, quando imersos num ambiente muito favorável à certeza, ensejam

\footnotetext{
27 A respeito do sistema italiano, Galgano disse que “aqui o direito nacional exige a avaliação dos interesses promovidos pelo contrato, e essa avaliação é influenciada pela uniformidade internacional do modelo contratual. É improvável que um juiz italiano julgue inválido um modelo contratual reconhecido como válido em todo lugar. [...] Mas a Corte de Cassação italiana, desde a década de 1960, sentiu a necessidade de mantê-lo válido. As decisões recentes baseiam sua ratio decidendi nas necessidades do comércio internacional: a garantia de boa execução é reconhecida como contrato atípico válido, que promove interesse digno de proteção ligado ao crescimento do comércio internacional e das relações interbancárias conexas. [...]. [Verifica-se a] permeabilidade de nosso sistema jurídico não somente a necessidades econômicas mas também a influências de modelos jurídicos codificados no exterior” (GALGANO, 1995, p. 99-107).

${ }^{28}$ Pode-se reformular isso como externalidades de rede, garantia de cumprimento, etc.
} 
contratos mais curtos, mas criam, por outro lado, barreiras consideráveis à inovação. Há ainda outros motivos pelos quais isso acontece.

Em primeiro lugar, os juízes de todas as tradições jurídicas tendem a vislumbrar nas normas legais, ainda que dispositivas, a encarnação de um ideal de justiça e, em razão disso, podem vir a aplicá-las de modo a afastar as cláusulas voluntariamente ajustadas ${ }^{29}$. Pela importância atribuída aos tipos contratuais, isso tende a acontecer de forma ainda mais acentuada nos países românicos.

Além disso, a par do comportamento judicial, as lições da economia comportamental sugerem que vieses cognitivos tornam as normas dispositivas muito mais aderentes (“sticky”) do que a teoria econômica neoclássica prevê. As normas legais dispositivas ensejam a manifestação de um efeito de ancoragem (anchoring bias) que descreve a influência dos pontos de referência iniciais sobre as decisões. Depois que os pontos de referência iniciais - ou âncoras - estão estabelecidos, os ajustes neles operados tendem a ser demasiadamente pequenos, de forma que a ancoragem acaba desviando os juízos finais em direção à âncora (KAHAN; KLAUSNER, 1996, p. 347-363). Embora o efeito de ancoragem possa ser usado para explicar a persistência do jargão contratual (KAHAN; KLAUSNER, 1996, p. 347-363), a mesma explicação é ainda mais persuasiva quando aplicada às normas legais, já que a âncora é mais conhecida e mais facilmente disponível para as partes.

A presença de um viés de preferência em relação àquilo que já se conhece (alternativamente denominado "viés do status quo" [status quo bias], "efeito de dotação" [endowment effect] ou “disparidade entre preços de oferta e demanda” [offer-asking price gap]) mostra que a alocação inicial de direitos pode afetar as preferências por esses direitos. Isso quer dizer que as trocas, inclusive no que diz respeito às cláusulas contratuais, tendem a ocorrer com menos frequência do que se esperaria num mundo coaseano, caracterizado por baixos custos de transação (KOROBKIN, 1998a, p. 1.583-1.584; 1998b, p. 608). Nos países de direito romanogermânico, o efeito desse viés é catalisado não apenas pela prevalência de contratos típicos, mas também pela tendência de sistematização e pela pressão por uma harmonização da prática negocial.

Embora o viés do status quo seja universal, a maior importância dos tipos legais em sua tradição possivelmente reduz ainda mais a propensão dos advogados romanistas a pensar fora da caixa das regras e formas contratuais existentes, e potencialmente mais receosos de se arrepender de

\footnotetext{
${ }^{29}$ Cf., p. ex., SCHWARTZ, 2003, p. 541-596.
} 
um desvio em relação às cláusulas já conhecidas ${ }^{30}$. Isso permite, por um lado, a redução dos custos de transação mediante a redução da complexidade por meio da padronização, mas, por outro lado, representa uma barreira à inovação contratual, conduzindo, ao menos historicamente, a instrumentos contratuais mais curtos e homogêneos. A existência de regras dispositivas e tipos contratuais é relevante, como deve ter ficado claro agora, porque negociar algo diferente dos padrões legais não vem sem custo (AYRES; GERTNER, 1992, p. 729-762). Além do mais, os mesmos fatores que, como a literatura internacional identificou, influenciam a aderência ao jargão contratual e às cláusulas contratuais padronizadas, aplicam-se também aos tipos contratuais (ou jargão legislativo, por assim dizer).

Assim como a prevalência do boilerplate é evidente nos Estados Unidos, no direito continental verifica-se, em medida talvez ainda maior, o apego aos tipos contratuais. Isso se deve às externalidades de aprendizado e de rede associadas ao uso dessas cláusulas, cuja recorrência assegura a funcionalidade de seu conteúdo e a familiaridade dos advogados e participantes do mercado, bem como uma economia de custo (KAHAN; KLAUSNER, 1997, p. 713-720). Porém, as externalidades de aprendizado e de rede relacionadas aos tipos contratuais são mais intensas que aquelas ligadas ao jargão contratual, pois o conhecimento dos tipos contratuais e sua jurisprudência é presumivelmente ainda mais difuso e disseminado.

Consequentemente, os tipos contratuais ensejam, de duas maneiras, contratos mais curtos. Em primeiro lugar, por todos os motivos mencionados acima, as partes preferem muitas vezes aterse aos padrões legais, caso em que as regras do negócio podem estar escritas unicamente na lei, e não no contrato que as partes redigem. Em segundo lugar, a incerteza acerca da interpretação das formas desviantes desestimula as partes a especificarem circunstâncias que não são contempladas pela lei. As regras da interpretação jurídica elevam o custo da execução judicial de contratos complexos e assim induzem as partes a usarem contratos mais simples (SCHWARTZ; WATSON, 2004, p. 2). Isso é especialmente verdadeiro na tradição romano-germânica.

Logo, o sistema romanista fomenta contratos mais curtos e conservadores, enquanto o norte-americano favorece contratos mais longos e deixa maior margem para a inovação (mesmo que, também nos Estados Unidos, o uso prolongado de jargão mal redigido mostre que o aperfeiçoamento das formas contratuais é mais exceção do que regra). Constatadas as diferenças,

\footnotetext{
30 De acordo com a teoria da aversão ao arrependimento, os indivíduos sentem mais arrependimento quando consequências indesejáveis se seguem à ação do que quando se seguem à inação. Nesse caso, deixar deliberadamente a posição de status quo gera um risco maior de arrependimento que deixar de passar do status quo para um estado alternativo (KOROBKIN, 1998b, p. 657).
} 
cumpre examinar as vantagens e desvantagens de cada sistema. Embora a doutrina romanogermânica tenda a justificar a importância dos contratos típicos (sejam juridicamente ou socialmente) em termos do valor da certeza e dos riscos de deixar às partes uma grande margem de liberdade, disso não se segue necessariamente que seja essa a única função que eles cumprem. De fato, os doutrinadores continentais nem sempre dispensam um tratamento instrumental ao direito.

A primeira vantagem comparativa do direito continental é que ele propicia uma economia de custos de transação. As numerosas normas legais, que abrangem diferentes tipos de contrato, podem tornar desnecessário para as partes redigir suas próprias cláusulas, o que propicia uma economia de tempo no processo de negociação e em relação aos honorários de advogados. Porém, a capacidade das normas legais dispositivas de reduzir os custos de transação depende da medida em que elas são geralmente desejáveis pelas partes, isto é, se elas refletem o que as partes teriam querido. Por um lado, a aceitação generalizada do conteúdo das normas dispositivas implica a tendência de as partes concordarem com seu conteúdo. Por outro lado, agora deve estar claro que a adoção dos tipos contratuais pode ser simplesmente um sinal da dificuldade de se afastar das disposições legais.

Ainda que as generalizações tendam a ser inexatas, parece razoável afirmar que nos países de civil law a maioria das normas legais dispositivas tende a compor padrões "majoritários”, que refletem as normas que a maioria das partes teria querido caso tivesse negociado a respeito ${ }^{31}$. Por serem feitas sob medida para diferentes modalidades de contrato, elas também têm mais probabilidade de atender às necessidades das partes e propiciar assim uma economia de custos de transação.

Embora seja benéfico para a maioria, esse sistema cria novos obstáculos para que as partes insatisfeitas redijam o acordo que quiserem. Depois que as normas dispositivas estão fixadas, negociar algo diverso delas e disputar em juízo as cláusulas desviantes acarreta custos majorados. Esse é exatamente o motivo pelo qual alguns doutrinadores dizem que, dada a dificuldade de se talhar bons padrões para as necessidades heterogêneas das empresas, deveria haver somente muito

\footnotetext{
${ }^{31}$ Para a afirmação de que o objetivo das normas dispositivas é refletir os interesses típicos que podem ser atribuídos às partes de um tipo específico de contrato, cf. os autores alemães CANARIS; GRIGOLEIT, 2004, p. 445-464. Esse é exatamente o paradigma tradicional para avaliar a eficiência dos padrões legais: eles devem proporcionar as cláusulas que as partes teriam querido se não houvesse custos de transação. Cf., p. ex., EASTERBROOK; FISCHEL, 1991; SCHWARTZ, 1988, p. 353-361. Os teóricos criticaram esse paradigma majoritário (“o que as partes teriam querido”) como critério exclusivo para normas dispositivas eficientes. Muitas vezes, um padrão minoritário ou padrão punitivo pode alcançar fins eficientes forçando as partes a contratar algo diverso dele e revelar informações no processo de negociação. Cf., p. ex., AYRES; GERTNER, 1989, p. 87; AYRES; GERTNER, 1999, p. 1.591. Tais críticas, porém, não afetam a conclusão de que, se as normas dispositivas apresentarem um caráter majoritário, a maioria das partes poderá redigir contratos mais curtos em decorrência disso.
} 
poucas normas dispositivas (SCHWARTZ; SCOTT, 2003, p. 541-601). De outra parte, vale ressaltar que, contrariamente à maior parte das economias de custos de transação, que acarreta maiores custos de execução (SCOTT; TRIANTIS, 2006) ${ }^{32}$, a adoção dos tipos contratuais também resulta numa economia substancial dos custos de execução. A familiaridade dos tribunais e advogados, bem como uma jurisprudência sólida e numerosos comentários acadêmicos, tornam a interpretação das normas legais cada vez mais previsível.

Saber qual é mais vantajoso, se o sistema anglo-saxônico ou o de direito continental, depende do seguinte tradeoff. Um grande número de tipos contratuais com normas dispositivas majoritárias reduz os custos de transação e de execução para a maioria das partes, mas aumenta os custos de mudança nos casos em que os esquemas legais de uso geral não oferecem a solução mais eficaz para um caso dado. O common law, inversamente, não ajuda em si mesmo a reduzir os custos de transação e de execução (ainda que o jargão contratual possa servir de substituto inferior para os tipos contratuais), mas torna relativamente mais fácil para as partes inovarem quando seu negócio não for enquadrado adequadamente pelas formas contratuais padrão. Não é fácil determinar neste momento para qual lado pende a balança, mas, assim como o jargão ajuda as partes, nos países de common law, a tirar proveito de certos benefícios dos tipos contratuais, a tradição romanista só pôde progredir implementando mecanismos que tornam a inovação menos custosa.

Um possível compromisso compatível com o gosto romanista seria abandonar a ideia de que o legislador não deve fazer mais do que consolidar o que a prática criou, bem como aumentar o número de contratos. O consenso prevalecente no direito romano-germânico é que a prática social é um pré-requisito para a regulação legal dos contratos; as tentativas legislativas de criar novos tipos contratuais seriam estéreis - argumentam os doutrinadores -, pois nada garante que essas novas formas seriam atraentes na prática (STIGLITZ, 1994, p. 146) ${ }^{33}$. Todavia, não existe motivo para que isso necessariamente aconteça. A duplicata brasileira, por exemplo, foi uma inovação legislativa extremamente bem-sucedida no campo dos instrumentos de pagamento, que não tinha um equivalente comparável a ela na prática ou no direito comparado ${ }^{34}$.

\footnotetext{
32 Scott e Triantis (2006) apontam a alocação de custos entre o momento inicial (custos de redação contratual mediante especificação de cláusulas e possíveis circunstâncias) e o momento final do processo de negociação contratual (custos de execução para provar e adjudicar o significado de cláusulas contratuais vagas) como uma ferramenta que explica a modelagem contratual. Ao adotar os tipos legais, as partes reduzem os custos de transação e execução, e essa compensação entre alocação de custos nos momentos inicial e final não ocorre.

${ }^{33}$ Iturraspe (1989, p. 998) afirma que “a ideia de tipificação contratual como fruto da imaginação da legislatura é inteiramente falsa. Seria a mesma coisa que criar formas que não fossem úteis na prática, já que ninguém ou poucos tirariam proveito delas. A tipificação legal deve ser precedida pela tipificação social”.

${ }^{34}$ Lei $n^{\circ} 5.474$, de 18 de julho de 1968.
} 
Um dos principais obstáculos à inovação contratual é que, embora a parte que inova arque com todos ou com a maior parte dos custos de estruturar uma forma ou cláusula contratual pioneira, ela pode não granjear a maior parte dos benefícios, pois tais criações não são patenteáveis ou facilmente protegíveis (SCHWARTZ; SCOTT, 2003). Embora haja indícios de que os pioneiros ainda gozem de alguns benefícios no mercado, graças à sua reputação de profissionais inovadores (FRAME; WHITE, 2004, p. 116-130), a presença de externalidades positivas tende a manter a inovação em níveis subótimos. Isso cria condições potencialmente promissoras para a intervenção estatal, já que as instituições públicas podem investir na criação de formas contratuais mais eficazes que, de outra forma, não surgiriam.

\section{NOTAS CONCLUSIVAS}

Não obstante o padrão tradicional até aqui descrito, observa-se na atualidade uma clara tendência de mudança quanto à ideia de que os advogados de formação romano-germânica terão uma postura tradicional no seu comportamento profissional. O processo bastante conhecido de americanização (ou anglicização) do direito e da advocacia também exibe seus efeitos no que toca à modelagem contratual. Escritórios dos EUA e da Grã-Bretanha e seus associados tomaram uma parcela crescente do mercado jurídico nos países românicos e impuseram suas práticas profissionais. Afinal, é válido presumir que, ao contratar um escritório norte-americano renomado no exterior, os clientes esperam receber o mesmo estilo de advocacia. E contratos longos, agressivos e detalhados são marca registrada dos escritórios de advocacia conceituados oriundos do common law.

Martin Shapiro há muito constatou a crença generalizada na Europa de que os negócios jurídicos da União Europeia teriam migrado para Londres porque os advogados ingleses seriam mais hábeis que os advogados continentais na inovação jurídica capaz de facilitar as novas relações comerciais transnacionais em evolução (SCHAPIRO, 1993, p. 37-39). Contudo, atribuir características inovadoras unicamente a advogados ingleses ou norte-americanos, como se estas estivessem desconectadas do sistema jurídico em que eles militam, parece demasiado simplista. A ocorrência de mais inovação na Inglaterra e nos Estados Unidos é inteiramente compatível com a tese aqui articulada, no sentido de que esses países são mais favoráveis à inovação do que os sistemas continentais. Enquanto os clientes valorizarem a inovação (como aparentemente o fazem), é plausível que eles tendam a associar a inovação a certos escritórios, e não a certos países. Como 
os advogados inovadores reagirão num cenário jurídico mais conservador é algo que ainda está por ser observado ${ }^{35}$.

Por toda parte, é notável a tendência no sentido de contratos mais longos e mais inovadores. Quanto ao tamanho dos contratos, porém, uma advertência é necessária. Nem toda a extensão dos contratos norte-americanos pode ser atribuída à especificação de circunstâncias ou ao uso de jargão contratual; grande parte é devida a uma prolixidade injustificada. Como apontou Farnsworth, os advogados anglo-saxônicos são mais prolixos que seus equivalentes continentais, e os advogados norte-americanos são os mais prolixos de todos ${ }^{36}$. Tudo que os advogados anglosaxônicos escrevem tende a ser mais longo que o equivalente escrito por advogados românicos, e isso também vale para as leis (FARNSWORTH, 1996, p. 232). Quanto à redação contratual, grande parte dessa prolixidade deve-se à assimetria de informação entre advogados e clientes; os advogados se esforçam para fazer seu trabalho parecer sofisticado, e o vocabulário complicado é um instrumento para se atingir esse fim $^{37}$.

Ainda assim, a exportação dessas formas verborrágicas, combinada com a indiferença pelas particularidades dos sistemas de direito contratual continental, levanta dúvidas quanto à eficiência absoluta desse desenvolvimento. De fato, existe o risco de que, apesar do glamour do qual se revestem os longos e complexos instrumentos contratuais dos escritórios anglo-saxões, eles se tornem disfuncionais nos sistemas romanistas. Ou pode ser que a simpatia dos sistemas romanistas pelo que se tornou prática os leve suavemente a aceitar essa nova realidade. Nesse caso, a eficiência da disciplina particularizada ao caso concreto terá ganhado a batalha contra a homogeneidade e a economia nos custos de transação e execução.

Historicamente, o papel de destaque dos advogados nos sistemas de common law, previsivelmente acompanhado por altos honorários, é inteiramente compatível com as formas contratuais extensas de lavra particular que caracterizam a prática transacional anglo-americana. Como afirma Max Weber, os interesses econômicos de uma classe de advogados bem organizada e poderosa foram o motivo pelo qual a Inglaterra não adotou o direito romano, mais "racional”, no

\footnotetext{
35 Para um questionamento da eficácia dos contratos de estilo norte-americano à luz dos preceitos europeus continentais de interpretação contratual, cf. WIEGAND, 1996, p. 146.

36 A observação é de E. Allan Farnsworth (1996, p. 227-231) durante seu trabalho, como representante dos EUA, perante a Comissão das Nações Unidas para o Direito Comercial Internacional, para a negociação e redação que culminou na Convenção das Nações Unidas sobre Contratos de Compra e Venda Internacional de Mercadorias de 1980 (Convenção de Viena).

${ }^{37}$ Os advogados sabem que alguns clientes, até mesmo sofisticados, ficam desapontados se o advogado escreve em linguagem simples e clara. Se as pessoas respeitam um documento porque ele parece jurídico e, assim, seria algo fora do comum, isso é uma forma de poder. As pessoas escrevem para "impressionar mais do que para se expressar, muitas vezes com resultados desastrosos”. Cf. MACAULAY et al., 2003, p. 746-747.
} 
fim da Idade Média, como aconteceu na Europa continental. Em suas palavras, os interesses pecuniários dos advogados na Inglaterra agiram para "stabilizing the official law and of adapting it to changing needs in an exclusively empirical way but also preventing its rationalization through legislation and legal science” (WEBER, 1968, p. 787) ${ }^{38}$.

No campo dos contratos, a resistência dos advogados ingleses à recepção do direito romano impediu a inserção da noção de tipos contratuais no common law e, portanto, gerou um ambiente mais favorável a contratos longos, detalhados e quiçá mais inovadores que no civil law. É certo que o fenômeno da tipificação contratual (e a consequente resistência dos juízes em acatar formas contratuais divergentes dos tipos legais) também se relaciona com o maior intervencionismo estatal nos contratos privados em países de tradição romanista (PARGENDLER, 2016) - os quais, não por acaso, tendem a exibir modelos de capitalismo distintos do paradigma liberal prevalente em países anglo-saxônicos (PISTOR, 2005). Seja como for, o aumento da participação de mercado dos escritórios anglo-americanos nos países de direito romano-germânico e a convergência no desenho contratual parecem sugerir que, apesar da alta subsequente dos custos de transação, os benefícios do estilo de redação contratual do common law superam suas despesas correlatas.

Na falta de provas mais concretas quanto às falhas de mercado que deturpam esses resultados, cabe agora ao sistema romanista reagir, seja para mitigar seu estimado regime dos tipos contratuais, seja para dele tirar proveito para promover a inovação por meio da iniciativa estatal, reduzindo assim os problemas associados às externalidades positivas da inovação contratual privada. O legislador não deve necessariamente se limitar a consolidar práticas comerciais, mas também investir na concepção de formas e cláusulas contratuais mais eficientes para diferentes tipos de operações econômicas. Dessa maneira, a inovação no civil law ocorreria de modo inteiramente compatível com sua tradição de certeza e homogeneidade na prática negocial, ao mesmo tempo que proporcionaria ganhos de eficiência na contratação privada.

\footnotetext{
${ }^{38}$ Max Weber (1968, p. 976) argumentando que "[t]he English and American adjudication of the highest courts is still to a great extent empirical, and specifically: an adjudication by precedents. In England, the reason for the failure of all efforts at a rational codification of law, as well as the failure to 'receive' the Roman law [at the end of the Middle Ages, when this occurred elsewhere in Europe], was due to the successful resistance against such rationalization offered by the great and centrally organized lawyers' guilds, a monopolistic stratum of notables from whose midst the judges of the high courts of the realm were recruited. They retained in their hands juristic training as an apprenticeship transmitting an empirical and highly developed technology, and they successfully fought all moves toward rational law emanating especially from the ecclesiastical courts, and, for a time, also from the universities, which threatened their social and material position [...]. The fight of the common law advocates against the Roman and ecclesiastical law, and against the power of the church in general, was to a considerable degree economically conditioned, namely by the lawyer's interest in fees; this is distinctly evidenced by the way in which the kings intervened in this struggle”.
} 


\section{REFERÊNCIAS}

AUDIT, Bernard. L'américanisation du droit: introduction. Archives de philosophie du droit, Paris, v. 45, p. 7-11, 2001.

AYRES, Ian; GERTNER, Robert. Filling Gaps in Incomplete Contracts: An Economic Theory of Default Rules. Yale Law Journal, New Haven, v. 99, p. 87-130, out. 1989.

Majoritarian vs. Minoritarian Defaults. Stanford Law Review, Stanford, v. 51, p. 1.5911.613, jan. 1999.

. Strategic Contractual Inefficiency and the Optimal Choice of Legal Rules. Yale Law Journal, New Haven, v. 101, p. 729-773, jan. 1992.

AZEVEDO, Álvaro Villaça. Contratos inominados ou atípicos. São Paulo: J. Bushatsky, 1975. 188 p.

AZEVEDO, Antônio Junqueira. Qualificação jurídica de "acordo operacional” (contrato atípico, complexo, com fortes elementos dos contratos de know-how e de mandato com administração). Contratos de duração e não-denunciabilidade dos contratos de duração determinada. Denúncia ilícita. Revista Forense, Rio de Janeiro, v. 101, n. 380, p. 239-255, jul./ago. 2005.

BETTI, Emilio. La tipicità dei negozi giuridici romani e la cosidetta atipicità del diritto odierno. In: BETTI, Emilio. Diritto, metodo, ermeneutica: scritti scelti. Milão: Giuffrè, 1991.

BITTAR, Carlos Alberto. Contratos comerciais. $3^{\mathrm{a}}$ ed. Rio de Janeiro: Forense universitária, 2003. $228 \mathrm{p}$.

BURNHAM, Scott J. The Contract Drafting Guidebook. $2^{\mathrm{a}}$ ed. Charlottesville: The Michie Company, 1992. $511 \mathrm{p}$.

CAGNASSO, Oreste; IRRERA, Maurizio. Concessione di vendita, merchandising, catering. Milão: A. Giuffrè, 1993.

CALKOEN, Willem. Globalization and the Future of the International Practice of Law from a European Perspective. In: DROLSHAMMER, Jens; PFEIFER, Michael (Ed.), The Internationalization of the Practice of Law. Haia: Kluwer Law International, 2001. cap. 9, p. 137150.

CANARIS, Claus-Wilhelm; GRIGOLEIT, Hans Christoph. Interpretation of Contracts. In: HARTKAMP, Arthur et al. (Ed.). Towards a European Civil Code. $3^{\mathrm{a}}$ ed. Nijmegen: Ars Aequi/Kluwer Law International, 2004. cap. 25, p. 445-464.

COSTA, Mário Júlio de Almeida. Direito das obrigações. 7ª ed. Coimbra: Almedina, 1998. 1030 p.

DE NOVA, Giorgio. Il tipo contrattuale. Padova: Cedam, 1974. 231 p.

DINIZ, Maria Helena. Tratado teórico e prático dos contratos. 5a ed. São Paulo: Saraiva, 2003. 
EASTERBROOK, Frank H.; FISCHEL, Daniel R. The Economic Structure of Corporate Law. Cambridge: Harvard University Press, 1991.

FARNSWORTH, E. Allan. A Common Lawyer's View of His Civilian Colleagues. Louisiana Law Review, Baton Rouge, v. 57(1), p. 227-231, 1996.

. Contracts. $4^{\mathrm{a}}$ ed. Nova Iorque: Aspen Publishers, 2004.

. Restatement of the Law Second, Contracts. Philadelphia: American Law Institute, 1979.

FRAME, W. Scott; WHITE, Lawrence J. Empirical Studies of Financial Innovation: Lots of Talk, Little Action? Journal of Economic Literature, Pittsburgh, v. 42(1), p. 116-144, 2004.

FRIEDMAN, Lawrence M. A History of American Law. 3ª ed. Nova Iorque: Touchstone, 2005.

GALGANO, Francesco. The New Lex Mercatoria. Annual Survey of International \& Comparative Law, San Francisco, v. 2, p. 99-110, 1995.

GARCIA, Manuel Lobato. Aproximación a la figura del merchandising. Revista de Derecho Mercantil, Madri, v. 195, p. 137-154, 1990.

GORDLEY, James. Contract, Property, and the Will - The Civil Law and Common Law Tradition. In: SCHEIBER, Harry N. (Ed.). The State and Freedom of Contract. Stanford: Stanford University Press, 1998. cap. 3, p. 66-88.

HENROT, Jacques. Classification and General Rules of Construction in French Law. In: YELPAALA, Kojo et al. (Ed.). Drafting and Enforcing Contracts in Civil and Common Law Jurisdictions. $3^{\mathrm{a}}$ ed. Deventer: Kluwer Law and Taxation Publishers, 1990.

HILL, Claire A.; KING, Christopher. How Do German Contracts Do As Much With Fewer Words? Kent Law Review, Chicago, v. 79(3), p. 889-926, 2004.

ITURRASPE, Jorge J. Mosset. Los contratos atípicos. Revista Jurídica Argentina La Ley, Buenos Aires, Tomo 1989-B, 1989.

KAHAN, Marcel; KLAUSNER, Michael. Path Dependence in Corporate Contracting: Increasing Returns, Herd Behavior and Cognitive Biases. Washington University Law Quarterly, St. Louis, v. 74, p. 347-363, 1996.

Standardization and Innovation in Corporate Contracting (or "The Economics of Boilerplate”). Virginia Law Review, Charlottesville, v. 83(4), p. 713-770, 1997.

KOROBKIN, Russell. Inertia and Preference in Contract Negotiation: The Psychological Power of Default Rules and Form Terms. Vanderbilt Law Review, Nashville, v. 51, p. 1.583-1.651, 1998a.

. The Status Quo Bias and Contract Default Rules. Cornell Law Review, Ithaca, v. 83(3), p. 608-687, mar. 1998b. 
LANGBEIN, John. Comparative Civil Procedure and the Style of Complex Contracts. American Journal of Comparative Law, Ann Arbor, v. 35(2), p. 381-394, abr. 1987.

LANGUI, André. Les contrats spéciaux dans l’histoire des obligations. In: CADIET, Loïc (Ed.). Le droit contemporain des contrats. Paris: Economica, 1987.

LAPERTOSA, Flavio. L'engineering. Milão: A. Giuffrè, 1993. 403 p. (Coleção Il Diritto Privato Oggi).

LUNDMARK, Thomas. Verbose Contracts. American Journal of Comparative Law, Ann Arbor, v. 49(1), p. 121-131, 2001.

MACAULAY, Stewart et al. Contracts: Law in Action, the Concise Course. $2^{\text {a }}$ ed. New Providence: LexisNexis, 2003.

MALAURIE, Philippe; AYNES, Laurent. Cours de droit civil. 2a ed. Paris: Cujas, 1989.

MARTINS, Fran. Contratos e obrigações comerciais. 15ª ed. Rio de Janeiro: Forense, 2000.

MERRYMAN, John Henry. The Civil Law Tradition: An Introduction to the Legal Systems of Western Europe and Latin America. 2ª ed. Stanford: Stanford University Press, 1985.

MEZZOMO, Marcelo Colombelli; FREIRE, Riano Valente. Breves apontamentos sobre o contrato de seguro. Revista Forense, Rio de Janeiro, v. 97, n. 356, p. 125-146, jul./ago. 2001.

MICHELON JR., Claudio. Direito Restitutório: enriquecimento sem causa, pagamento indevido, gestão de negócios. São Paulo: Revista dos Tribunais, 2007.

NICOLAS, Bernadette; TROGAN, Philippe. Le leasing en France: son développement, ses problems. Revue trimestrielle de droit commercial et de droit économique, Paris, v. 19, p. 49-57, 1966.

ORTIZ, Rafael Illescas. El "leasing”: aproximación a los problemas planteados por un nuevo contrato. Revista de Derecho Mercantil, Madri, v. 119, p. 73-114, jan./mar. 1971.

PARGENDLER, Mariana. The Rise and Decline of Legal Families. American Journal of Comparative Law, Ann Arbor, v. 60(4), p. 1.043-1.073, 2012.

2016.

The Role of the State in Contract Law: The Common-Civil Law Divide. Working Paper,

PARGENDLER, Mariana; SALAMA, Bruno Meyerhof. Direito e Consequência no Brasil: em busca de um discurso sobre o método. Revista de Direito Administrativo, Rio de Janeiro, v. 262, p. 95-144, jan./abr. 2013.

PINTO, Paulo J. da Silva. Dos contratos atípicos. Revista Forense, Rio de Janeiro, v. 40, n. 95, p. 14-198, 286-299, jul./set. 1943. 
PISTOR, Katharina. Legal Ground Rules in Coordinated and Liberal Market Economies. In: HOPT, Klaus et al. (Ed.). Corporate Governance in Context: Corporations, States, and Markets in Europe, Japan and the U.S. Oxford: Oxford University Press, 2006.

PLANIOL, Marcel. Classification synthétique des contrats. Revue Critique de Législation et de Jurisprudence, Paris, A53, T33, p. 470-486, 1904.

ROPPO, Enzo. O contrato. Coimbra: Almedina, 1988. 371 p.

SALAMA, Bruno Meyerhof. O que é pesquisa em Direito e Economia? Cadernos Direito GV, São Paulo, v. 5, n. 2, p. 5-58, mar. 2008.

SCHWARTZ, Alan. Proposals for Products Liability Reform: A Theoretical Synthesis. Yale Law Journal, New Haven, v. 97(3), p. 353-419, fev. 1988.

; SCOTT, Robert. Contract Theory and the Limits of Contract Law. Yale Law Journal, New Haven, v. 113(3), p. 541-619, 2003.

; WATSON, Joel. The Law and Economics of Costly Contracting. Journal of Law, Economics and Organization, Oxford, v. 20(1), p. 2-31, 2004.

SCOTT, Robert; TRIANTIS, George. Anticipating Litigation in Contract Design. Yale Law Journal, New Haven, v. 115(4), p. 814-866, jan. 2006.

SHAPIRO, Martin. The Globalization of Law. Indiana Journal of Global Legal Studies, Bloomington, v. 1(1), p. 37-64, 1993.

SILVA, Clóvis do Couto. Contrato de engineering. In: FRADERA, Maria Jacob (Ed.). O direito privado brasileiro na visão de Clóvis do Couto e Silva. Porto Alegre: Livraria do Advogado, 1997. cap. 7.

STARK, Tina L. (Ed.). Negotiating and Drafting Contract Boilerplate. Nova Iorque: ALM Publishing, 2003. 675 p.

STIGLITZ, Rubén S. Contratos: teoría general. Buenos Aires: Depalma, 1994.

TEEVEN, Kevin. A History of the Anglo-American Common Law of Contract. Nova Iorque: Greenwood Press, 1990.

THEODORO JÚNIOR, Humberto. Contrato de comissão no novo Código Civil. Revista Forense, Rio de Janeiro, v. 100, n. 372, p. 119-134, mar./abr. 2004.

VAN HECKE, Georges A. A Civilian Looks at the Common-Law Lawyer. In: REESE, Willis L. M. (Ed.). International Contracts: Choice of Law and Language. Nova Iorque: Oceana Publications, 1962. p. 5-10.

VASCONCELLOS, Pedro Pais de. Contratos atípicos. Coimbra: Almedina, 1995. 
WEBER, Max. Economy and Society. Nova Iorque: Bedminster Press, 1968.

WHITMAN, James. The Two Western Cultures of Privacy: Dignity versus Liberty. Yale Law Journal, New Haven, v. 113(6), p. 1.151-1.221, 2004.

WIEGAND, Wolfgang. Americanization of Law: Reception or Convergence? In: FRIEDMAN, Lawrence M.; SCHEIBER, Harry N. (Ed.). Legal Culture and Legal Profession. Boulder, CO: Westview Press, 1996. cap. 6, p. 137-152.

\title{
CONTRACT DESIGN IN COMPARATIVE PERSPECTIVE: REFLEXIONS ON THE RELATIONSHIP BETWEEN LEGAL TYPIFICATION AND CONTRACTUAL INNOVATION
}

\begin{abstract}
The differences in the style of contracts used in civil law and common law systems are well known. Traditionally, Anglo-Saxon agreements are longer, as well as more tailored and detailed, than those emerging from the civil-law tradition. However, the existing literature fails to provide a satisfactory explanation for this phenomenon. This article examines how the prominent role of contract types in the civil law tradition, and their lesser role in common law systems, affects the patterns of contract design observed in business practice. From a positive perspective, the Anglo-Saxon origin of a significant number of atypical contracts - such as the so-called “-ing” contracts (leasing, franchising, engineering, among others - suggests that the legal tradition may play an important role in shaping contract design. From a normative perspective, there is a tradeoff between a reduction in the transaction costs brought about by legislative contract types, on the one hand, and the disincentives created to innovation in contractual forms, on the other. Finally, the article concludes by reflecting on the future of drafting techniques in an era of globalization and on the possible role of the state in inducing contract innovation in the civil law tradition.
\end{abstract}

\section{KEYWORDS}

Contract design. Contract types. Common law. Economic analysis. 